\title{
The protection of the Baserri as an energy efficient building: the optimized insulation strategy
}

\author{
U. Gaztelu, A. De la Fuente, A. Azkarate \& J. Rodriguez \\ University of the Basque Country, ZAIN and GPAC, Spain
}

\begin{abstract}
The Baserri is the vernacular farm of the Basque Country and it is considered to be one of the most important elements of the Basque cultural and architectural heritage. Living spaces, stable, barn and workplace are gathered in the same compact and self-sufficient building that is, above all, an efficient productive system.

For almost 500 years, Baserris have always been able to adapt to the contemporary needs of the society, overcoming some periods of strong crisis. But nowadays they still have not found an answer to the latest social changes that took place during the industrial revolution of the XXth century, which brought the gradual emptying of these farms. Consequently, lots of them are currently being abandoned and demolished. Their preservation is at serious risk. In order to respond to this situation and with the goal of providing the best preservation possible for Baserris, this paper aims at an optimized insulation system for an efficient energetic refurbishment. Firstly, the architectural and bioclimatic features of these buildings will be analyzed and quantified, and then various efficient insulation strategies are going to be compared through energetic performance computer simulations. Finally, this paper will conclude with the proposal of the most efficient insulation strategy.

Keywords: Baserri, energy, refurbishment, heritage, monitoring.
\end{abstract}

\section{Introduction}

The Baserri, the most important Basque private heritage, is a compact architectural element that gathers the dwelling, workshop, store, stable, barn and granary [1]. It is a heritage whose different typologies in which it developed 
adopted the requirements for a self-sustainable way of agriculture and cattle farming. Built following logical construction methods and with durable materials, it features interesting landscape integration and basic bioclimatic design strategies.

The first traces of this building date back to the end the XV century, and since then this compact and enclosed architectural piece has adapted to the different requirements of the socioeconomic context throughout different stages in its history. However, the industrial revolution that took place on the XX century resulted in a severe crisis in the agricultural and stockbreeding sectors, which made the factory part of the Baserri lose its purpose and caused half of the indoor space to be left empty. This is why the preservation of this Basque heritage is currently at serious risk.

In order to tackle this problem and with the aim of providing a future for these buildings, this paper sets the optimized insulating strategies for an energy efficient refurbishment.

\section{Bioclimatic analysis}

\subsection{Theoretical analysis}

Apart from comprising several inner spaces, which serve different purposes, Baserris can be regarded as display of a complex passive design.

For instance, their location and orientation depends upon the topography and solar factors of the place where they are built. They do not take into account neither economic or social factors, nor ones such as proximity or accessibility. Instead, their main objective is to keep themselves warm and provide enough natural light for daily life and work [2].

Besides, bioclimatic logic lies beneath the internal layout of the Baserri.

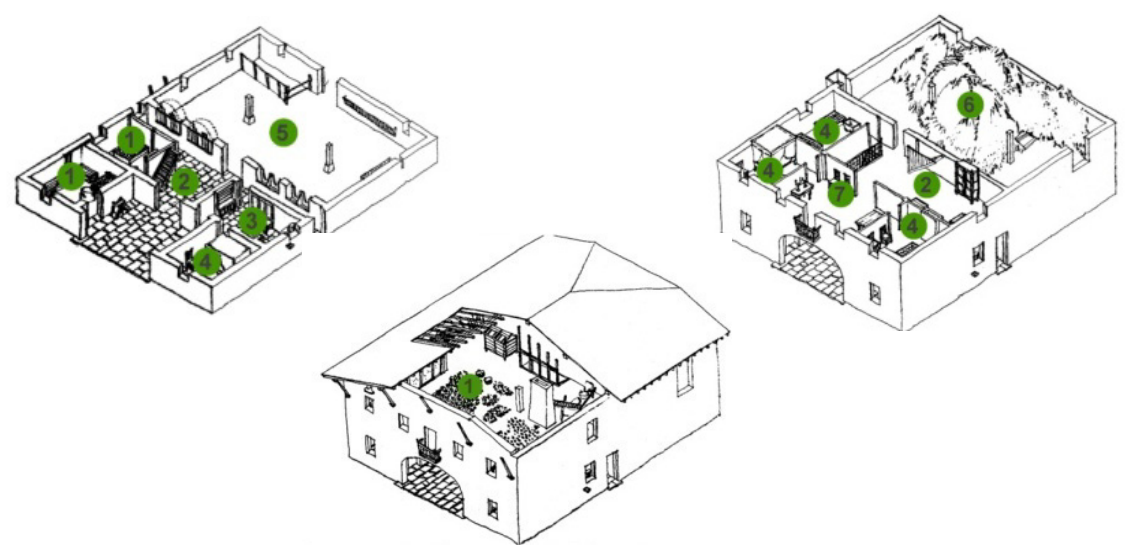

Figure 1: Internal distribution of the Biscayan Typology [3]. 
For example, the dwelling part faces south in order to make the most of the solar gains, so it is here where the main facade is placed. This side has the greatest number of windows to take advantage of these gains and the brightness. In addition, the barn where corn is left to dry is set on the third floor, a place whose exposure to continuous ventilation results in enormous heat loss.

During the XVII century, a stone wall separating the north and south parts began to be brought into the Baserris [4], which had a major impact on the building, concerning both fire safety and thermal response. The stable where livestock is kept is located on the ground floor of the north side. The stable works as a thermal cushion for the building and protects the dwelling side from north winds.

The straw loft or granary is placed above this room, and complies with two bioclimatic aspects: on the one hand, the straw prevents the heat coming from the animals in the stable from seeping upwards, and on the other hand it helps the northern side of the building maintain its role as a thermal cushion.
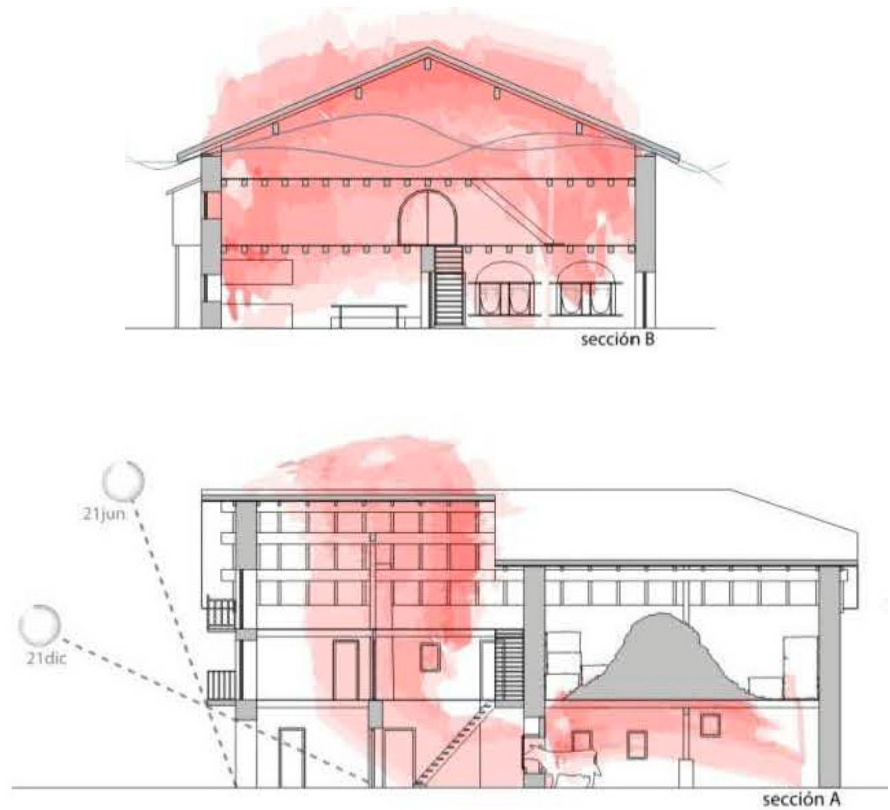

Figure 2: $\quad$ Thermal response [5].

\section{Construction}

The basic construction materials in a Baserri are stone, with which the main walls are built, and wood, used for the framed structure on the inside. Apart from their structural role, these elements, and especially the stone ones, play an essential one in the thermal response of the building. 
For instance, the external walls and the one separating the north and south parts of the building are 50-75 cm wide stone walls, which provide the building with remarkable thermal inertia and keeps internal temperatures constant.

The real impact of the bioclimatic factors mentioned in the previous part will be measured in a case study that consists in the monitoring of an actual Baserri and its subsequent verified simulation.

\section{Monitoring}

The Baserri chosen for these measurements was Torre, due to its current state of preservation and lack of use. This will allow us to demonstrate how Baserris work as a passive element.

\subsection{Torre Baserri}

Torre is located in the neighbourhood Gametxo in Ibarrangelu, Bizkaia, in a plot close to the crest of the mountain, which offers amazing views to the northwest over the Cantabrian Sea. It was built at the beginning of the XX century, in 1907, so it belongs to the latest tendency in farms that had changed into downsized and poor looking rural constructions back in the XIX century.

Once being in possession of some basic plans of the building [6], different data loggers have been placed throughout the building. The temperature and levels of humidity are measured, so that they can be compared with the results given by the computer simulation.

The following chart displays the results of the measurements carried out between 18th April 2012 and 1st December 2012.

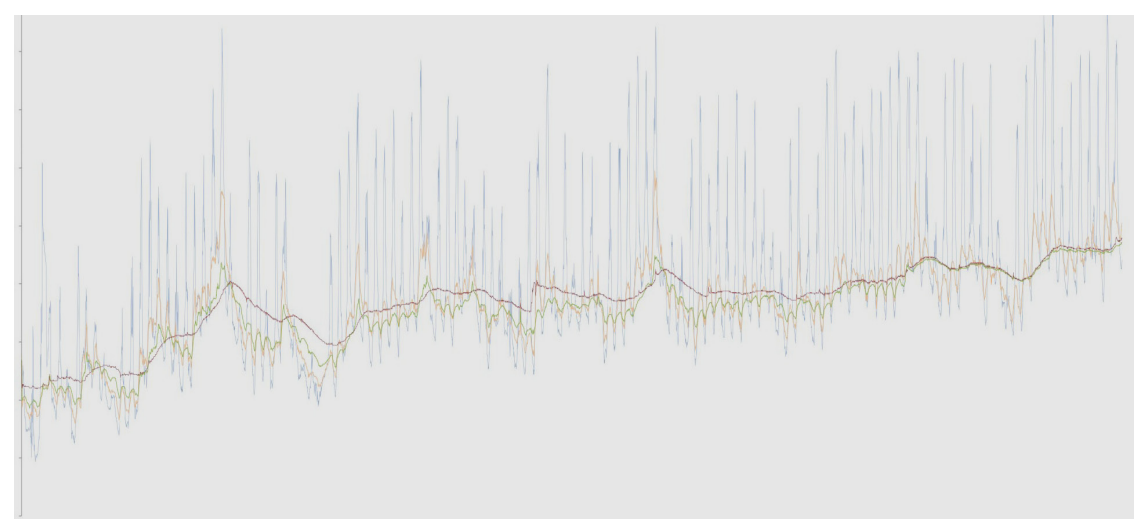

Figure 3: $\quad$ Torre Baserris’ monitoring results. 


\subsection{Interpretations}

\subsubsection{Inertia}

The first conclusion that can be drawn from the chart is the appropriate response of the thermal inertia of the Baserri. If internal and external temperatures are compared, it can be noticed that the former one fluctuates in a less significant way. This phenomenon is due to the influence of the external stone walls. However, the greater fluctuation that takes place at the straw loft is the result of it being in contact with the ventilated roof.

\subsubsection{Similarities in internal temperatures}

As the building is in disuse, the only active heating systems that the heat gains coming from the livestock and the stove in the kitchen could represent have vanished. Therefore, all the interior spaces have registered very similar temperatures.

\subsubsection{Cold winter, warm summer}

Although the temperatures recorded during the summer reached comfort levels, by the time April began, temperatures had dropped to nearly $12^{\circ} \mathrm{C}$. It can be concluded from these figures that the new strategies to be implemented must include thermal insulation as well as new heat gains.

\subsubsection{External temperatures}

Looking at the chart, there seems to be a sudden increase of external daily temperatures. This comes as a result of the location of one of the loggers, as it is placed on the western side exposed to direct sunlight. Hence this thermal leap.

\subsection{The simulation process}

Once the monitoring was concluded, these temperature measurements should be extended and extrapolated to a whole year's cycle in order to analyze the thermal response of the Baserri and also to be used as laboratory data. So a computer energy simulation of Torre is carried out to achieve this objective.

\section{Simulation}

The programme chosen to perform the simulation was Design Builder Energyplus v2.2. The first step was to convert all the information gathered during the monitoring process into input data for the programme. After that, a digital model of the current state of the Baserri had to be drawn so it could be compared with the real situation and allow the verification of the simulation.

\subsection{Input data}

\subsubsection{Climate data}

The first step consists in setting up the climate data, which can be taken from one of the files that the programme includes. In this case, the file "San Sebastian/ 
Igueldo" is the one that most approximates to the characteristics of the location of Torre. Both places share similar temperature and precipitation figures, their altitude does not differ significantly, and they are exposed to wind alike.

\subsubsection{Model/orientation/location}

The next step involved creating a simplified model based on the plans that had been obtained previously.

In respect of the surroundings, there are no actual exterior elements that could exert any influence on the energy performance of the building. Besides, the main facade was set to face east and the only elements considered to prevent solar gains are the balcony and the overhanging eaves.

Finally, regarding inner distribution, just the basic partitions and staircase voids were included in the modelling.

\subsubsection{Enclosure}

Once the model was finished, the materials of the main elements were set.

\subsubsection{Uses}

The use of the Baserri was established to reflect the current status of the building, as its lack of use had been the main reason to monitor it.

\subsubsection{Heating and ventilation systems}

As the building is in disuse, no active system was activated in order to be able to get the real energy performance of the building on its own in this first simulation.

Eventually, the data input process came to its end, giving way to the simulation of the virtual model of the Baserri.

\subsection{Simulation}

The first aim of the simulation is its own verification, that is, show that it represents reality in a faithful way. To attain that goal, it is necessary to draw a comparison between its results and the real measurements of Torre. Accordingly, the comparison will start and finish at the same time, even though the climate data in the programme do not exactly match the one gathered during the monitoring in 2012.

Figure 4 shows the results of the simulation carried out with Design Builder Energyplus v2.2 running between April 18th and December 1st.

Eventually, this figure is compared with the one resulting from the monitoring process, so as to be able to interpret them and draw some conclusions.

\subsection{Verification of the simulation}

When analyzing both figures, the divergence between both external temperatures must be taken into account, since the real data gathered during the monitoring process in 2012, and the average climate data in Donosti are likely to be different. Thus, both figures will display different external temperature levels. 


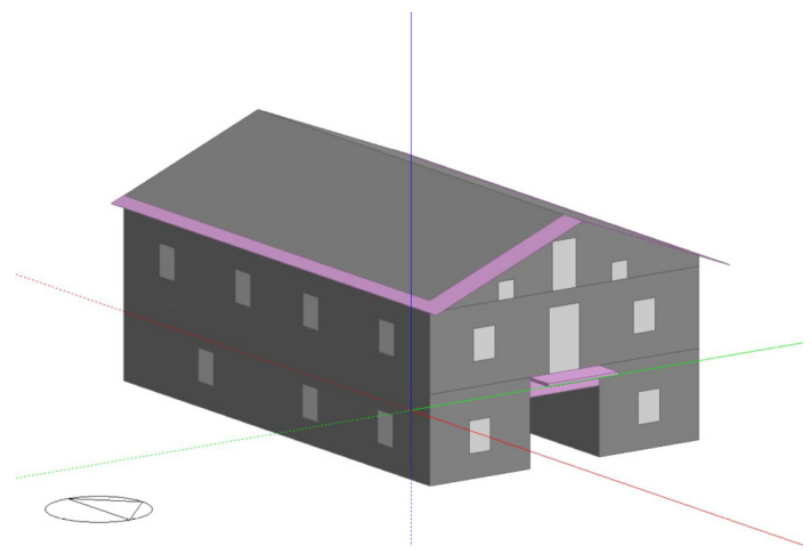

Figure 4: $\quad$ Torre Baserris’ simulation results.

\subsubsection{External-internal temperatures}

When these two charts are compared, attention must be drawn to the correlation between inside and outside temperatures. It is here where both cases prove to be similar, as the oscillation of internal temperatures is lower than the external ones, and they are $2-4^{\circ} \mathrm{C}$ higher.

\subsubsection{Thermal inertia}

Temperatures oscillate less on the inside than on the outside, so they keep constant. This way, it can be concluded that the thermal mass of the external wall fulfils its function in the model as well. However, the continuous ventilation of the granary prevents this from happening there too.

\subsubsection{Similarities in internal temperatures}

Without the presence of the animals and the kitchen having been disabled, the Baserri has been left out with no internal gains. Furthermore, internal air leaks and filtrations are considerably big. All these factors lead to the logic consequence of the internal temperatures similarity.

In conclusion, the computer simulation carried through with Design Builder Energyplus v2.2 software complies with the essential features of the energy performance of Torre. This way the verification of the virtual model allows it to be used to try and test strategies on it in the next step.

\subsection{Close cycle simulation}

After the verification of the energy simulation, the programme offers the possibility to perform another one to quantify the hygrothermal response of the building throughout a whole closed cycle, which enables the user to come up with different strategies to be implemented in the future.

Here are the close cycle simulation results. 


\subsection{Interpretation}

Together with the conclusions drawn before, this new simulations brings up the virtual winter data, which makes it possible to produce a new interpretation of the results.

\subsubsection{Between $10-14^{\circ} \mathrm{C}$ in winter}

The main conclusion is that temperature in the kitchen and stable ranges between 10 and $14^{\circ} \mathrm{C}$ for nearly half of the year. This reveals the need of the Baserri for a source of internal energy gains, so future strategies should target not only at insulating the building from the outside, but also at obtaining these gains in a passive way.

Once the close cycle simulation has been understood, the aim is to find the optimum insulating strategy.

\section{Insulating strategies}

In order to outline the insulating strategies for the Basque Baserris, Torre will be taken as translatable model so that all the data can be extrapolated to the general casuistry of the Baserris. First of all, two main assumptions had to be made:

\subsection{Assumptions}

On the one hand, the new use of the Baserri was set to dwelling, as it is the one with the highest energy demand. This way, it will be able to meet the needs and demands of any other function that could be considered.

On the other hand, the insulation of the whole building will be considered, excluding other types of refurbishment, such as the renovation of just the dwelling part of the original Baserri or even half of the building. This is considered as one of the limitations of this paper.

\subsection{Level of insulation}

First, it is necessary to read and interpret the current and future energy frame in order to set the level of insulation.

Nowadays, in accordance with the Spanish Construction Technical Code, the heating demand of a detached house can rise up to $61.9 \mathrm{kWh} / \mathrm{m}^{2}$, whereas the standard German Passivhaus, which is regarded as the reference to achieve the goals for 2020, needs to run with less than $15 \mathrm{kWh} / \mathrm{m}^{2}$ This means that when adapting the Spanish code to meet the European requirements, the energy demand should be cut down by $75 \%$, which involves a great economic investment in building and refurbishment projects.

Taking that into account, this initial investment must prove to be worth in the long term. As it is shown in the chart below, the optimum and most cost effective solution turns out to be insulating with materials with thermal transmittance values between 0.25 and 0.40 . 


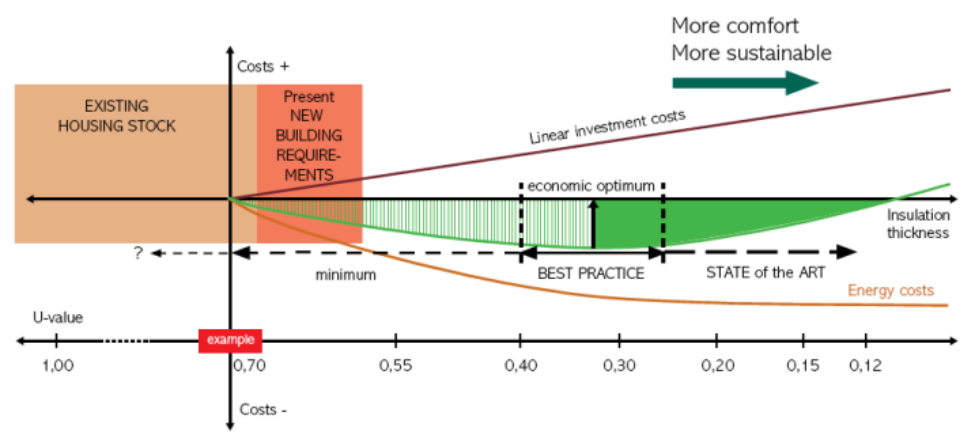

Figure 5: $\quad$ Cost optimal graphic [7].

\subsection{Application on Baserris}

To quantify the energy related impact of these measures on the Baserris, the own materials of the building are taken into account [chart 01.], so it is possible to establish the insulation type and dimensions to reach the goal of 0.25$0.40 \mathrm{~W} / \mathrm{m}^{2} \mathrm{~K}$. Concerning the type, materials which have the currently standard thermal transmittance value of $0.04 \mathrm{~W} / \mathrm{m}^{2} \mathrm{~K}$ are the ones selected.

\subsection{Comparison}

When comparing different thickness values, all other variables are discarded. Therefore, the pattern to follow will be heating and insulating the Baserri, as well as placing that insulation on the outside, the reason being the better hygrothermal response provided by this type of insulating system compared to the internal one, as it makes use of the building's own thermal inertia. This will lead to an extrapolation value so as to fulfil the whole casuistry.

Then, taking an insulation material with a $0.04 \mathrm{~W} / \mathrm{m}^{2} \mathrm{~K}$ thermal transmittance value into consideration, it is analysed what the thermal response of the Baserri would be with different standard insulation thickness values. This way, it will be possible to set the optimum one.

$8 \mathrm{~cm}$ : the new $U$ values show that the new thermal transmittance of the external walls has changed to $0.388 \mathrm{~W} / \mathrm{m} 2 \mathrm{~K}$, while the roof has a value of 0.411 and the floor 0.374 . As it can be seen, all these figures range between the limits of $0.25-0.40$. Besides, the energy demand has dropped to $38.41 \mathrm{KWh} / \mathrm{m}^{2}$ per year, which means that it has been reduced to the $33.84 \%$ of the initial status.

$10 \mathrm{~cm}$ : new thermal transmittance values: the external walls 0.325 the roof 0.341 and the floor 0.307 . They seem to be in the middle of the cost optimal values described before, and the energy demand would be cut down to $35.64 \mathrm{KWh} / \mathrm{m}^{2}$ per year, $31.40 \%$. 
$12 \mathrm{~cm}$ : reduces the thermal transmittance value of the external walls to 0.279 , 0.291 the roof and 0.26 the floor. Besides, the new energy demand is $33.61 \mathrm{KWh} / \mathrm{m}^{2}$ per year and the efficiency is $70.39 \%$.

\subsection{Interpreting the comparison}

Two main readings have to be made prior to drawing the conclusions of this comparison:

First, all three sizes are placed within the cost optimal range. The constructive elements of the Baserris allow the $U$ values of the fabric to be between 0.26 and $0.41 \mathrm{~W} / \mathrm{m}^{2} \mathrm{~K}$ with the help of an 8,10 or $12 \mathrm{~cm}$ thick insulation which has a thermal transmittance of $0.04 \mathrm{~W} / \mathrm{m} 2 \mathrm{~K}$.

Apart from that, they all have a remarkable impact on the energy performance of the building, as the initial demand of $113 \mathrm{KW} / \mathrm{m}^{2}$ per year drops to values ranging from 33 or 39 . This way, the efficiency of the Baserris would increase dramatically, which is highly recommendable according to the authors of this research.

\section{$6.610 \mathrm{~cm}$ : optimum thickness}

Even though 8, 10 and $12 \mathrm{~cm}$ thick insulating systems are able to meet the demands of current and future energy frames and economic realities, the basic strategy based on $10 \mathrm{~cm}$ insulation is considered to be the optimum one, since it matches the most suitable point of the cost economic measure enabling the control of the initial economic investment. Moreover, it also proves to be able to reach a low energy demand: $35 \mathrm{KWh} / \mathrm{m}^{2}$ per year.

Therefore, it comes as a conclusion that the $U$ values of the external walls, roof and floor should be $0.33,0.34$ and $0.31 \mathrm{~W} / \mathrm{m}^{2} \mathrm{~K}$ respectively.

\subsection{Optimizing the strategies}

These last figures come as a result of implementing continuous insulation as a general strategy, which means placing insulation the same way over all the parts of the building. However, this strategy can be optimized according to the basic principles of environmental design.

It is broadly known that each part of a building works in a different way depending on its location and orientation, so the roof, floor and external walls will behave in dissimilar ways under certain conditions. Thus, there is room for improvement for the $10 \mathrm{~cm}$ thick insulation general strategy.

We are talking about both economic and energy optimization, as the objective is to improve the energy performance without having to increase the economic investment, the factor that heat moves upwards and the roof is in contact with external temperatures, moving part of the insulation placed on the floor up to the roof would improve the performance of the building.

That way, the final insulating strategy will bring the energy demand of the Baserri down to $30.16 \%$, reaching a value of $34.16 \mathrm{KWh} / \mathrm{m}^{2}$ per year. 


\subsection{New limits of the thermal transmittance}

So, in a nutshell, these are the thermal transmittance values that the new law should require:

$$
\text { Facade: } 0.325 \mathrm{~W} / \mathrm{m}^{2} \mathrm{~K} \quad \text { Roof: } 0.29 \mathrm{~W} / \mathrm{m}^{2} \mathrm{~K} \quad \text { Floors: } 0.375 \mathrm{~W} / \mathrm{m}^{2} \mathrm{~K}
$$

\subsubsection{Internal or external insulation}

Once the thermal transmittance values have been set, it is possible to quantify the difference between placing the insulation on the internal or external sides of the fabric.

As it has been explained before, establishing an external insulation with the aforementioned thickness and $U$ value results in an energy demand reduction of $69.90 \%$ from the original state, $34.16 \mathrm{KWh} / \mathrm{m}^{2}$ per year. On the other hand, an internal insulation would increase that demand up to $43.20 \mathrm{KWh} / \mathrm{m}^{2}$ per year, which means a fall of $61.94 \%$.

In conclusion, placing the insulation on the external side seems to be option to be recommended when it comes to energy savings, as the efficiency decreases by $8 \%$ when placing it on the inside. However, despite the fact that this recommendation points in one direction, it is necessary to take other aspects into consideration and see the whole picture. This way, future laws should allow the strategy of placing the insulation on the internal side in order to keep a balance between the heritage value, the constructive logic and the energy criteria.

\section{Conclusion}

With the goal of finding a solution to the problem Baserris have been enduring for the last hundred years and providing them with quality preservation, this research aims at offering the optimized insulating strategy for the energyefficient refurbishment of these buildings.

At the beginning, a typological and bioclimatic analysis of the Baserris was carried out, which provides an insight of their energy performance. In order to offer scientific proof to this theoretical analysis, an actual Baserri that meets the necessary conditions, Torre, was monitored. This monitoring confirms the behaviour and performance deduced from the theoretical analysis.

In the next stage, in order to extend all the gathered data to a whole year cycle and be able to quantify the effect of the insulation levels to be applied, an energy computer simulation of the selected Baserri was carried out. Afterwards, the results given by the simulation are compared with the real figures obtained through the monitoring process, which permits to simulate the effects of the new input data.

On the way to find the most efficient insulating strategies, first the Spanish and European energy context is analyzed, and then new insulating levels are established in accordance with economic efficiency criteria. Finally, the impact these measures would have on the Baserris is assessed and then optimized, to 
end up with a final optimized insulating strategy that sets new thermal transmittance values for the constructive elements- facade: $0.325 \mathrm{~W} / \mathrm{m}^{2} \mathrm{~K}$; roof: $0.29 \mathrm{~W} / \mathrm{m}^{2} \mathrm{~K}$; floor: $0.375 \mathrm{~W} / \mathrm{m}^{2} \mathrm{~K}$.

In the end, it is deduced that this paper has satisfactorily fulfilled its commitment, as it has been able to adapt to current and future realities. It has offered specific insulating strategies for an energy efficient refurbishment of Baserris, based on logic insulating sizes and measures.

Although there is much work left to do, this research can be a small step to provide the solution to a current important problem and allow the preservation of the most important Basque heritage

\section{Limitations of the research}

Despite the fact that the goal was achieved, this paper has encountered some limitations on its way. First of all, this research has not considered all the possible ways in which a Baserri can be refurbished, as neither the use assigned nor the volume or area to be renovated. And finally, windows have not been taken into account when working on insulating levels, though they are an important part of the fabric and source of considerable filtrations and thermal bridges.

\section{References}

[1] Santana, A., et al., Euskal Herriko baserriaren arkitektura, historia eta tipologia. pp. 12. 2001.

[2] Beristain, B., BaserriBerri, pp. 06-10, 2010.

[3] Gaztelu, U., Guidelines for refurbishment of baserris, pp. 18, 2011.

[4] Santana, A. Arqueología, Urbanismo y Arquitectura. pp. 290. 1989.

[5] Beristain, B., BaserriBerri, pp. 21, 2010.

[6] Gaztelu, U. Rehabilitación energética del caserío: hacia un modelo de diagnosis. pp20-22 2012.

[7] Ecofys, U-values for better energy performance of buildings, pp. 12, 2007. 